\title{
Developing an Effective Conceptual Framework for Safety Behaviour in Construction Industry
}

\author{
Chaher Zid ${ }^{1 *}$, Narimah Kasim ${ }^{1}$, Hocine Benseghir ${ }^{2}$, Muhammad Nomani Kabir $^{3}$ and \\ Abdullah Bin Ibrahim² \\ ${ }^{1}$ Faculty of Technology Management, Tun Hussein Onn University of Malaysia, Batu Pahat, \\ Malaysia \\ ${ }^{2}$ Faculty of Engineering Technology, Universiti Malaysia Pahang Lebuhraya Tun Razak 26300 \\ Gambang, Kuantan Pahang, Malaysia. "Corresponding author (abi@ump.edu.my) \\ ${ }^{3}$ Faculty of Computer Systems \& Software Engineering, Lebuhraya Tun Razak 26300 Gambang, \\ Kuantan Pahang, Malaysia.
}

\begin{abstract}
The construction industry involves one of the most hazardous occupation for workers due to complex management processes, environmental issues, work pressure and heavy and complicated equipment involved in modern construction projects. Despite the advancement of technology in the construction industry, an escalating number of fatal accidents occur because of the human errors and the unsafe behaviours. In this research, an analysis for previous studies has been conducted to define all safety behavioural factors in construction industry for improving the safety performance in construction industry. All the studies were categorised in accordance with their methodologies, analytical methods, variables, and the findings in order to build an effective conceptual framework. The framework comprises of three main categories that incur direct impact toward the safety behaviour in construction industries, namely: (a) organizational factors, (b) safety climate factors, and (c) individual factors. Each category has own variables which make a total of 16 factors for all categories. The framework facilitates to assess the effectiveness of a construction industry, identify the deficiencies and the weakness, and create procedures to manage the accident in future by controlling the safety behaviour of employees.
\end{abstract}

\section{Introduction}

Construction fatality has remained the highest among all industries, making about $20 \%$ of all work environment fatalities in 2015, with more than 2 fatality accidents per day, mostly at the work places [1]. Researchers investigated various studies relating industry size with the damage, fatality and illness rates [2-7] . The younger workers may accept work injuries as "part of the job" due to the lack of experience in their own work [8]. The safety behaviour is an essential indicator, where the industries use the safety behaviour in a

\footnotetext{
* Corresponding author: zchaherz@gmail.com
} 
proactive manner "before the actual event", to evaluate the safety performance [9]. Many studies have discussed the importance of the safety behaviour as a leading indicator [9-12]. Consequently, it enables to assess the effectiveness of the safety system, distinguish the deficiencies and the weaknesses, and create procedures to manage the accident in future by controlling the safety behaviour of employees.

\section{Background of research}

In 2014, 4386 cases of fatalities were reported in the all sectors of industry, while 899 cases were recorded only in construction industries, showing that more than one out of five labours deaths are from construction sector[13, 14]. According to (OSHA) [15], the labours in construction face the highest risk compared to the other industry sectors in terms of occupational injuries and illnesses. A total of 31,943 accidents occurred in 2017 in Malaysia, where construction sector made the third highest number of accidents, according the Social Security Organisation (SOCSO). The worrying statistics may affect the development due to the number of death and injury in the modern age.

Through the statistics provided by DOSH, a short calculation was done on the latest 100 fatal accidents in all Malaysian industry. The majority of fatal accidents occurred in the construction industry involving 50 cases, while the rest of the industry had 50 fatal cases. Thus, severity of accidents with construction sector in Malaysia can be noticed with compared to the other industries. Furthermore, $32 \%$ of the recorded fatal accidents have not gotten any causes according to the report issued by[16], while $21 \%$ of these fatal accidents occurred because of unsafe working procedures, different reasons were given about $47 \%$ of the fatal accidents as shown in Figure 1.

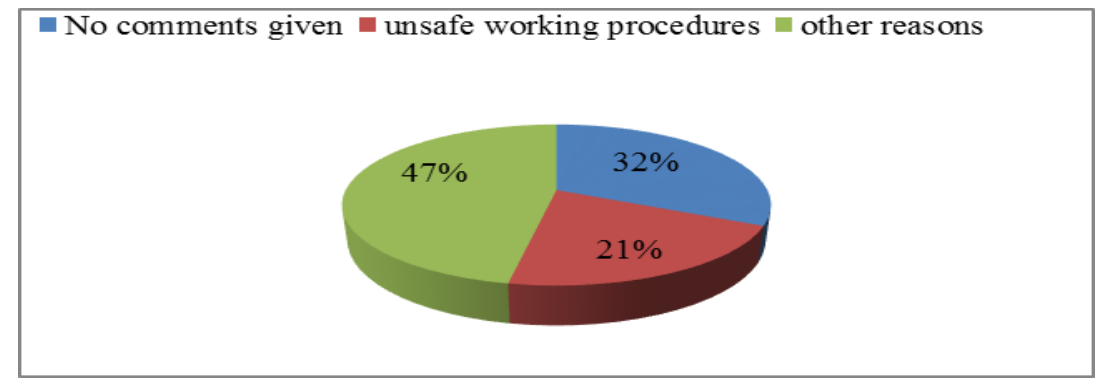

Fig.1. Fatal accidents in Malaysian construction industries from 12/06/2015 to 11/09/2017 [16]

Malaysia construction industry experienced 453 cases of death investigated by Department of Occupational Safety and Health (DOSH) in the last 6 years as shown in Figure 2, where it accounts more than $40 \%$ of the total number of fatal deaths across all industries in Malaysia [17]. Moreover, the number of construction incidents increases with more complexity of construction projects, recently the frequency of fatal accidents in Malaysian construction is accelerating compared to other industries when the highest death recorded on last year 2016 as 106 dead [17]. This tends to support the significance of the safety of construction projects and search carefully about the causes of the accidents and develop new risk analysis methods to ease the management of the construction safety [18]. 


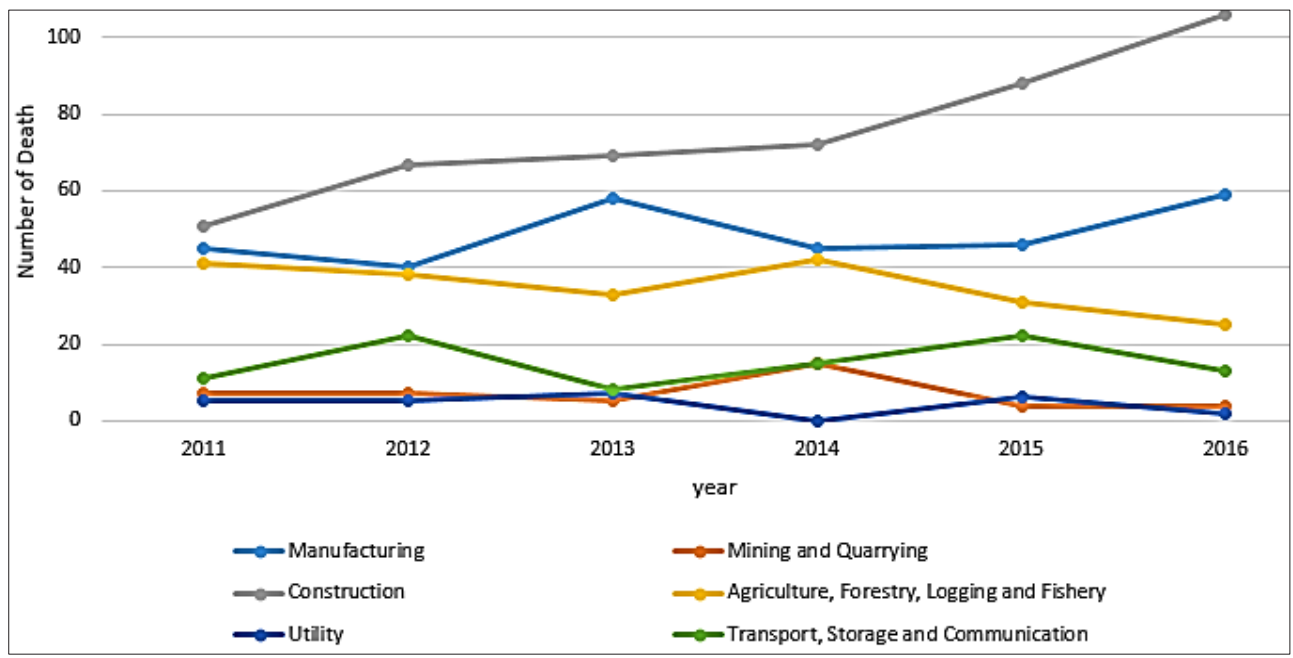

Fig. 2. Death statistics by sectors in Malaysia (2011-2016) [17]

Both unsafe condition and unsafe behaviour must be treated to be wiped out to imply a thoroughly protection plan against construction accidents. Safety managers and practitioners are implementing the safety intervention differently towards all levels of workplace safety.

However, all attention will tend to concentrate on the site condition, once an accident or near miss happens because the physical proof can be easily accumulated to represent the accident to apply prior amendments to avoid the same accidents in future [19-21]. However, unsafe behaviours have allocated some relatively little efforts to reduce or delete the risky acts in the workplaces. Blackmon, et al. [22] reported that unsafe action is the cause of $98 \%$ of accidents. Thus, the management of construction projects should reconsider the implementation of construction management safety by preventing dangerous behaviours. Labours' safety acts need to be closely inspected and adjusted if necessary to deter unsafe behaviours. In light of these insights, effective handling of safety issues at the construction workplace has become the main attention of many researchers and experts. Unsafe behaviour was found as the root of all accidents in the construction industry in Taiwan [23] and other construction sites [20, 24, 25]. Thus, it is inevitable to examine the human factors and the safety behaviour of workers in construction industry.

\section{Methodology}

The methodology of this research focuses on the latest bibliographic databases. In the previous section, we summarized that despite the latest high tech and the advanced risk assessment applied in construction industry, still the accident records are very scary in terms of death and injury. Many fatal accidents occurred with Malaysian construction industries. The background presents the studies that investigated the safety behavioural factors at construction industries. Our methodology is presented as follows. First, the keywords, titles, and abstracts have been highlighted using Mendeley in the main databases published work between 2008 and 2018. Fundamentally, these databases involved ProQuest, Social Sciences Full Text, Web of Science, Science Direct, etc. The keywords of this research have been selected to be "safety behaviour factors" and "construction Industry" in order to extract the relevant previous studies as shown in Table 1. All reference lists of articles have been searched manually. Next, substantial studies were identified after 
deleting the duplicates through Mendeley software. These studies were then selected based on the main safety behaviour factors namely: organizational factors, safety climate factors and individual factors. The abstracts and the titles were accordingly reviewed and analysed. Then, in order to determine all variables which have a positive influence on safety behaviours in construction industry, all relevant studies were finalised accordingly as shown in Figure 3.

All extracted variables were categorized based on their contributory in the previous studies into three main factors. Basically, the trustworthiness of the concluded data was retrieved evaluated based on study context, methods of data collection, analysis process, key findings and the contribution.

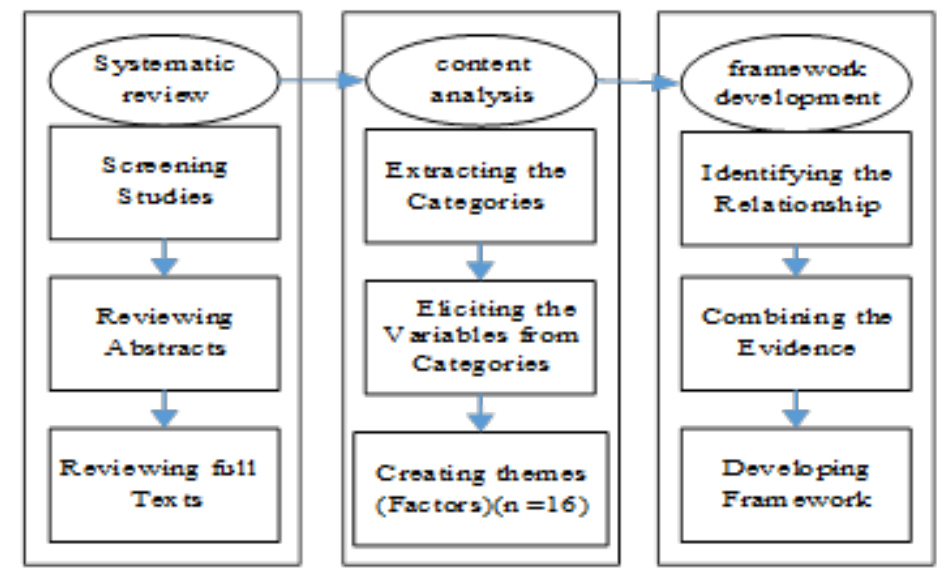

Fig. 3. Flow diagram of study design.

\section{Results and discussion}

The outcomes of this research paper are mainly to investigate the safety behaviour factors in the construction industry and clarify the fact of the relationship between all these factors based on previous studies. The conceptual framework is built to identify these relationships to be advised for future researches. Detailed description of the all data extracted from the entire studies that met the inclusion criteria is presented to meet the objectives this study. In the reviewed studies, 16 variables were adopted to determine their association with safety behaviour in construction industry. These variables were grouped into three contributory factors: Organizational factors, safety climate factors, individual factors.

\subsection{Organizational factor}

The Organizational factors play an important role to insure the safety behaviour in construction industry. Many factors were all determined to improve the safety behaviour such as administrative support, organizational legality, training, sufficient resources and so on. In this context, the future researches can validate and approve the suggested safety behaviour framework for management team to utilise it as a guide to enhance the investigation and the assessment of accidents. Jitwasinkul, et al. [26] conducted an extensive study in this regard and discovered twenty-two organizational factors. But, this study only includes seven key organizational factors: learning, communication, reward, safety culture, leadership, empowerment and management commitment. The same key 
factors have been used by Hadikusumo, et al. [27] to build Bayesian network for safety behaviour. Consequently, these factors are adopted for this study.

\subsection{Safety climate factors}

Safety climate is a summary of molar perceptions that employees share about their work environment [28]. The level of analysis of some organizational constructs such as climate, safety climate and related constructs participation, leadership affect, and technology is open to debate [29]. The authors in [30] investigated safety climate at both organizational and subunits levels, and found that the group-level safety climate mediates the relationship between organizational safety climate and individual safety behaviour. Many factors have been derived from Safety climate according to the previous studies. For the current study, five factors which have been highlighted by many authors [31,32] are adopted to present the safety climate impacts on safety behaviours.

\subsection{Individual factors}

Many authors have proven that the individual factors have positive influence on the safety behaviours. The following individual factors: education, work experience and the safety knowledge which have great positive influence on safety behaviour as demonstrated by [31] and been used to develop the safety behaviour model. Furthermore, another two factors were brought from the study of [33] namely; safety motivation, and safety compliance. Through the previous studies, we found that job satisfaction has a good positive impact on the safety behaviour, thus it was added to this study. The following discussion is about of all mentioned individual factors.

\subsection{Conceptual framework for construction industry}

The matter of fact for this study is built under previous researchers as shown in Table 1. Besides the information summarized on the Table 2 which have been extracted from literature review, the concept of this research is to combine all key factors to build an effective conceptual framework for safety behaviour. 
Table 1. Safety Behavior Factors

\begin{tabular}{|c|c|}
\hline Safety Behaviour Factors & Authors \\
\hline Learning & Organizational Factors \\
\hline Communication & {$[26,27,34-39]$} \\
\hline Leadership & {$[26,27,34,40-45]$} \\
\hline Reward & {$[26,27,34,46-50]$} \\
\hline Empowerment & {$[26,27,34,54-53]$} \\
\hline Safety culture & {$[26,27,34,61-65]$} \\
\hline Safety attitude & {$[21,26,27,31,32,34,66-69]$} \\
\hline \multicolumn{2}{|c|}{ Safety Climate Factors } \\
\hline Management Commitment & {$[26,27,32,34,70-76]$} \\
\hline Safety Management System & {$[26,27,32,34,61,77-82]$} \\
\hline Clients /Employees Involvement & {$[32,33,71,87,83-86]$} \\
\hline Production pressure & {$[31,32,90-94]$} \\
\hline & {$[31,32,95-102]$} \\
\hline Experience (work and education) & {$[32,33,95,98,103-110]$} \\
\hline Safety Knowledge & {$[115-118]$} \\
\hline Safety Motivation & Individual Factors \\
\hline Safety Compliance & \\
\hline Job Satisfaction &
\end{tabular}

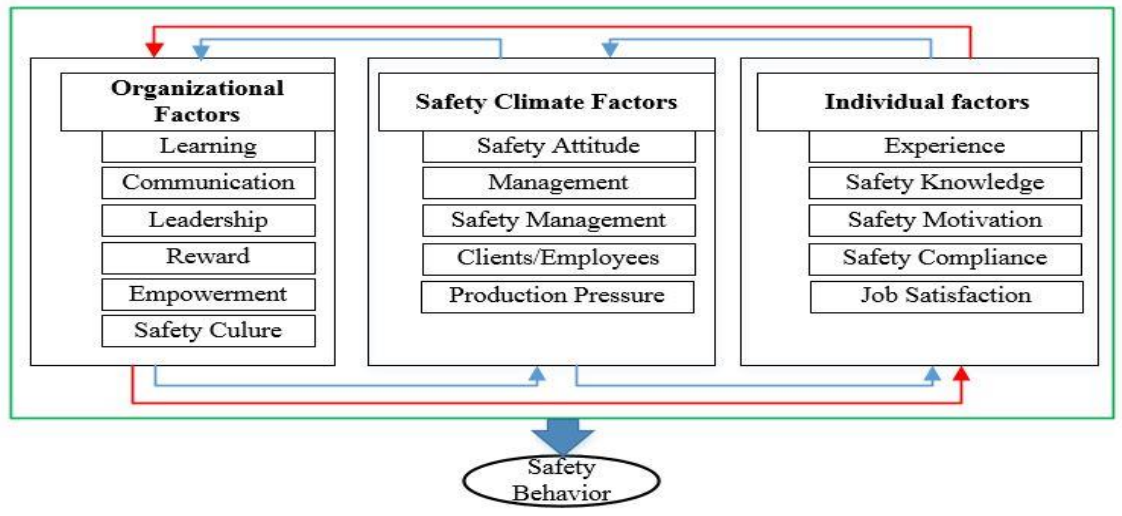

Fig. 4. Conceptual framework of safety behaviour model

In short, organizational factors, safety climate factors and individual factors $[27,33,77$, 87, 119-122] are combined for the first time to develop an effective conceptual framework for the safety behaviour in construction industry. The organizational factors (Learning, Communication, and Leadership, reward system, empowerment, and safety culture) have a positive relationship with safety behaviour[26, 27, 34] and have being utilized to build Bayesian network model for safety behaviour by Hadikusumo, et al. [27]. But, safety culture was excluded as a key factor and was not used as variable to build the Bayesian Network model; however, it will be evaluated in these studies as many researchers found good correlation with safety behaviour in construction industry in Malaysia [111, 123, 124].

Safety Climate Factors (Safety attitude, Management Commitment, Safety Management System, Clients Involvement, Production pressure) have proven a great positive relationship with safety behaviour and can be utilized as variable to build Bayesian network model for safety behaviour by [31-33]. Finally, individual factors (experience, safety knowledge, safety motivation, Safety Compliance and Job Satisfaction) have a good 
positive connection with safety behaviour and were used to build model for the safety behaviour using Bayesian network model [31, 32] and SEM model [33]. Additionally, job satisfaction will be evaluated in this research since it has a good correlation with safety behaviour [118, 122]. Figure 4 presents the framework of research and setting accordingly the Dependent Variables (safety behaviour) and independent variable of this study (Organizational factors, Safety Climate factors and Individual factors). These factors have been extracted from literature review, and the relationship is investigated among all factors demonstrated by previous studies. By using this idea, the conceptual framework in Figure 4 was built accordingly.

\section{Overall discussion}

The study of precondition safety using empirical methods and their connection to organizational characteristics remain challenging in the theoretical terms. In this regard, the current research has generalised the range and nature of all factors influencing safety behaviour in construction industry with a detailed conceptual framework. Based on the implemented extensive literature, theoretical or conceptual studies were rarely engaged by the researchers compared to substantial methodological studies executed in this context. To illustrate, many studies have been reviewed and concluded the factors influencing the safety behaviour in construction industry. The major conceptual ambiguity was identified while doing the preliminary research about safety behaviour. The necessary for an effective direction towards the conceptual matters popped out to be advised especially in this construction industry. Thus, the review highlighted the fast escalating pattern of fatal accidents construction industry and some conceptual issues related safety factors behaviour in order to give a better understanding of the connections between the causes and the accidents on one hand, and the theory and empirical findings on the other hand within the importance of an integrated conceptual model. Additionally, through the previous studies, the relationships of contributory factors safety factors were identified base on the Bayesian Network concept. Result indicates the inputs and the outputs of the conceptual framework. Firstly, the inputs were categorized in three different categories organizational factors, safety climate factors and individual factors; while, the safety behaviour presents the output of this conceptual model. Among all these preconditions factors, the development of a conceptual model of safety behaviour offers a number of advantages for decision makers to enhance the safety performance in construction industry.

Hypothetically, the coordinated model gives a conceptual framework to distinguish the structures of safety behaviour scales including the contributory factors as recorded in this paper. Besides, this relevant framework provides a typical language that decreases the probability of uncertainty in safety performance. Researchers may use this conceptual framework as reference for the future studies related to human safety behaviour at workplace in all industries. Furthermore, based on the three dimensions of safety behaviour factors; (i) the organizational, (ii) the safety climate and (iii) the individual factors, the applied model can be utilized to incorporate both proximal and distal factors of safety behaviour to develop analytical models for multivariate analyses.

The framework can be utilized for safety assessment and risk management. In practice, the decision makers may use the outcome of this coordinated framework to achieve a high level of safety in the construction sector. Safety assessment and risk management techniques should not discontinue at premature stage and fail to recognize the root causes of the occurred accidents. Knowing the real causes of accidents is important to develop effective preventive safety methods and thus, all critical failures prior to an accident or unsafe behaviours in construction industries need to be examined and actions must be taken to avoid a disaster. 


\section{Conclusion}

The world witnesses a rapid economic development and industrialization which lead to a very high frequency of accidents. The construction industry continues to remain as the most hazardous sector compared to other industries. The need to improve the safety policy in construction industries becomes inevitable, and the researchers need to investigate the root causes of occurred accidents. This paper reviewed the safety behaviour in construction industry and appeared to be multifactorial. The factors: organizational factors, safety climate factors and individual factors were incorporated. The result of the review strongly supports the organizational factors, the safety climate factors and the individual factors to be the input for the proposed conceptual framework, and the safety behaviour represents the output. This paper also highlighted the lack of studies related to accidents investigation, the root causes of accidents and neglecting the unsafe behaviour of employees in the construction industry. The researchers, practitioners and experts can utilise the conceptual framework to better understand the variable affecting the safety behaviour and performance. However, to determine the correlation and the consistence among all factors, further research is required to determine the influence mechanism of distal factors and proximal factors on safety behaviour. This will provide extra information and get a better understanding of the labours' experiences, their perception towards handling the risk at workplace for more effective prevention of the accidents.

This research is supported by a project no. RDU1703117 from Universiti Malaysia Pahang.

\section{Reference}

1. B. o. L. S. (BLS), (2016).

2. B. J. Poulin, S. J. P., and H. K. L., American Journal of Industrial Medicine, vol. 51, no. 9, pp. 701-713, (2008).

3. B. Fabiano, F. Currò, and R. Pastorino, Safety Science, vol. 42, no. 7, pp. 587-600, 2004/08/01/ (2004).

4. F. Paul and A. Simon, British Journal of Industrial Relations, vol. 42, no. 3, pp. 461480, (2004).

5. J. M. Mendeloff, C. Nelson, K. Ko, and A. Haviland, Small businesses and workplace fatality risk: an exploratory analysis. Rand Corporation, 2006.

6. M. Tim, D. Charles, W. Joseph, W. Nick, B. Heather, and F. Rongwei, American Journal of Industrial Medicine, vol. 45, no. 4, pp. 361-370, (2004).

7. K. Page, Journal of Safety Research, vol. 40, no. 2, pp. 85-95, 2009/01/01/ (2009).

8. A. H. Okun, R. J. Guerin, and P. A. Schulte, Journal of Safety Research, vol. 59, pp. 43-51, 2016/12/01/ (2016).

9. J. Hinze, S. Thurman, and A. Wehle, Safety Science, vol. 51, no. 1, pp. 23-28, 2013/01/01/ (2013).

10. M. Grabowski, P. Ayyalasomayajula, J. Merrick, J. R. Harrald, and K. Roberts, Safety Science, vol. 45, no. 10, pp. 1013-1043, 2007/12/01/ (2007).

11. S. Mahmoudi, F. Ghasemi, I. Mohammadfam, and E. Soleimani, Safety and Health at Work, vol. 5, no. 3, pp. 125-130, 2014/09/01/ (2014).

12. S. C. Payne, M. E. Bergman, J. M. Beus, J. M. Rodríguez, and J. B. Henning, Journal of Loss Prevention in the Process Industries, vol. 22, no. 6, pp. 735-739, 2009/11/01/ (2009).

13. B. o. L. S. (BLS), (2014).

14. O. S. a. H. A. (OSHA), (2016).

15. O. S. a. H. A. (OSHA), (2017). 
16. D. o. O. S. a. H. (Dosh), October 05, 2017b (2017b).

17. D. o. O. S. a. H. (Dosh), (22 June, 2017).

18. J. Hinze, C. Pedersen, and J. Fredley, Journal of Construction Engineering and Management, vol. 124, no. 1, pp. 67-71, (1998).

19. F. E. Gould and N. E. Joyce, Construction Project Management. Pearson, 2013.

20. R. M. Choudhry, Accident Analysis \& Prevention, vol. 70, pp. 14-23, 2014/09/01/ (2014).

21. M. Shin, H.-S. Lee, M. Park, M. Moon, and S. Han, Accident Analysis \& Prevention, vol. 68, pp. 95-105, 2014/07/01/ (2014).

22. R. B. Blackmon and A. K. Gramopadhye, Journal of Construction Engineering and Management, vol. 121, no. 2, pp. 166-171, (1995).

23. C.-F. Chi, S.-Z. Lin, and R. S. Dewi, Accident Analysis \& Prevention, vol. 72, pp. 359-369, 2014/11/01/ (2014).

24. E. Sawacha, S. Naoum, and D. Fong, International Journal of Project Management, vol. 17, no. 5, pp. 309-315, 1999/10/01/ (1999).

25. M. Zhang and D. Fang, Construction Management and Economics, vol. 31, no. 3, pp. 207-222, 2013/03/01 (2013).

26. B. Jitwasinkul and B. H. W. Hadikusumo, Journal of Civil Engineering and Management, vol. 17, no. 4, pp. 520-528, 2011/12/01 (2011).

27. B. H. W. Hadikusumo, B. Jitwasinkul, and A. Q. Memon, Procedia Engineering, vol. 171, pp. 131-139, 2017/01/01/ (2017).

28. D. Zohar, Journal of Applied Psychology, vol. 65, no. 1, pp. 96-102, (1980).

29. K. J. Klein, F. Dansereau, and R. J. Hall, Academy of Management Review, vol. 19, no. 2, pp. 195-229, (1994).

30. D. Zohar and G. Luria, Journal of applied psychology, vol. 90, no. 4, p. 616, (2005).

31. Q. Zhou, D. Fang, and X. Wang, Safety Science, vol. 46, no. 10, pp. 1406-1419, 2008/12/01/ (2008).

32. I. Mohammadfam, F. Ghasemi, O. Kalatpour, and A. Moghimbeigi, Applied Ergonomics, vol. 58, pp. 35-47, 2017/01/01/ (2017).

33. B. H. W. Guo, T. W. Yiu, and V. A. González, Safety Science, vol. 84, pp. 1-11, 2016/04/01/ (2016).

34. B. Jitwasinkul, B. H. W. Hadikusumo, and A. Q. Memon, Safety Science, vol. 82, pp. 264-273, 2016/02/01/ (2016).

35. N. Gotcheva, P. Oedewald, M. Wahlström, L. Macchi, A.-L. Osvalder, and H. Alm, Safety Science, vol. 81, pp. 90-98, 2016/01/01/ (2016).

36. B. Endroyo, B. E. Yuwono, D. Mardapi, and Soenarto, Procedia Engineering, vol. 125, pp. 83-88, 2015/01/01/ (2015).

37. S. Maslen and H. Ransan-Cooper, Safety Science, vol. 94, pp. 52-60, 2017/04/01/ (2017).

38. C. Charvet, J.-L. Chambon, F. Corenwinder, and J. Taveau, Journal of Loss Prevention in the Process Industries, vol. 24, no. 3, pp. 242-248, 2011/05/01/ (2011).

39. F. Drogoul, S. Kinnersly, A. Roelen, and B. Kirwan, Safety Science, vol. 45, no. 1, pp. 129-153, 2007/01/01/ (2007).

40. V. Kaskutas, A. M. Dale, H. Lipscomb, J. Gaal, M. Fuchs, and B. Evanoff, Journal of Safety Research, vol. 41, no. 3, pp. 221-227, 2010/06/01/ (2010).

41. V. Kaskutas, A. M. Dale, H. Lipscomb, and B. Evanoff, Journal of Safety Research, vol. 44, pp. 111-118, 2013/02/01/ (2013).

42. L. M. Kath, K. M. Marks, and J. Ranney, Safety Science, vol. 48, no. 5, pp. 643-650, 2010/06/01/ (2010).

43. P. Kines, L. P. S. Andersen, S. Spangenberg, K. L. Mikkelsen, J. Dyreborg, and D. Zohar, Journal of Safety Research, vol. 41, no. 5, pp. 399-406, 2010/10/01/ (2010). 
44. G. Sherbina, Transportation Research Procedia, vol. 20, pp. 602-607, 2017/01/01/ (2017).

45. P. X. W. Zou, P. Lun, D. Cipolla, and S. Mohamed, Safety Science, vol. 98, pp. 50-69, 2017/10/01/ (2017).

46. T. Zuofa and E. G. Ocheing, Procedia Engineering, vol. 196, pp. 1011-1017, 2017/01/01/ (2017).

47. Z. $\mathrm{Wu}, \mathrm{A} . \mathrm{T}$. W. Yu, and L. Shen, Waste Management, vol. 60, pp. 290-300, 2017/02/01/ (2017).

48. C. Wu, F. Wang, P. X. W. Zou, and D. Fang, International Journal of Project Management, vol. 34, no. 5, pp. 789-805, 2016/07/01/ (2016).

49. C. Wu, D. Fang, and N. Li, International Journal of Project Management, vol. 33, no. 8, pp. 1665-1679, 2015/11/01/ (2015).

50. X.-P. Chen, M. B. Eberly, T.-J. Chiang, J.-L. Farh, and B.-S. Cheng, Journal of Management, vol. 40, no. 3, pp. 796-819, (2014).

51. K. B. Kozhimannil et al., The Joint Commission Journal on Quality and Patient Safety, vol. 39, no. 8, pp. 339-348, 2013/08/01/ (2013).

52. L. Schlamb and K. Fisher, Clinical Simulation In Nursing, vol. 8, no. 8, p. e403, (2012).

53. E. S. Geller, Accident Analysis \& Prevention, vol. 16, no. 5, pp. 457-463, 1984/10/01/ (1984).

54. U. Cheasakul and P. Varma, Contaduría y Administración, vol. 61, no. 3, pp. 422-440, 2016/07/01/ (2016).

55. R. D. GhalichKhani and M. Hakkak, Procedia - Social and Behavioral Sciences, vol. 230, pp. 413-421, 2016/09/12/ (2016).

56. D. Y. K. Tong, D. Rasiah, X. F. Tong, and K. P. Lai, Safety Science, vol. 72, pp. 190198, 2015/02/01/ (2015).

57. B. G. de Miranda et al., American Journal of Infection Control, vol. 44, no. 6, p. S88, (2016).

58. Z. Chen, L. Li, and T. Li, Tourism Management, vol. 58, pp. 276-285, 2017/02/01/ (2017).

59. J. Hanaysha, Procedia - Social and Behavioral Sciences, vol. 229, pp. 298-306, 2016/08/19/ (2016).

60. R. Allahyari, B. shahbazi, S. M. Mirkamali, and K. Kharazi, Procedia - Social and Behavioral Sciences, vol. 30, pp. 1549-1554, 2011/01/01/ (2011).

61. R. A. Machfudiyanto, Y. Latief, R. Arifuddin, and Y. Yogiswara, Procedia Engineering, vol. 171, pp. 405-412, 2017/01/01/ (2017).

62. J. Edwards, J. D. Davey, and K. Armstrong, Procedia Manufacturing, vol. 3, pp. 4991-4998, (2015).

63. S. E. Biggs, T. D. Banks, J. D. Davey, and J. E. Freeman, Safety Science, vol. 52, pp. 3-12, 2013/02/01/ (2013).

64. S. Zheng and J. Chen, Systems Engineering Procedia, vol. 4, pp. 460-467, 2012/01/01/ (2012).

65. D. Fang and H. Wu, Safety Science, vol. 57, pp. 138-149, 2013/08/01/ (2013).

66. I. Schröder, D. Y. Q. Huang, O. Ellis, J. H. Gibson, and N. L. Wayne, Journal of Chemical Health and Safety, vol. 23, no. 1, pp. 12-23, 2016/01/01/ (2016).

67. I. Donald and D. Canter, Journal of Loss Prevention in the Process Industries, vol. 7, no. 3, pp. 203-208, 1994/01/01/ (1994).

68. O.-1. Siu, D. R. Phillips, and T.-w. Leung, Journal of Safety Research, vol. 34, no. 2, pp. 199-205, 2003/04/01/ (2003).

69. M. Findley, S. Smith, J. Gorski, and M. O’neil, Safety Science, vol. 45, no. 8, pp. 875889, 2007/10/01/ (2007). 
70. C. Pinion et al., Safety Science, vol. 93, pp. 70-75, 2017/03/01/ (2017).

71. K. Amponsah-Tawaih and M. A. Adu, Safety and Health at Work, vol. 7, no. 4, pp. 340-346, 2016/12/01/ (2016).

72. M. H. Forouzanfar et al., The Lancet, vol. 388, no. 10053, pp. 1659-1724, 2016/10/08/ (2016).

73. D. Paşaoğlu, Procedia - Social and Behavioral Sciences, vol. 207, pp. 315-324, 2015/10/20/ (2015).

74. O. Abudayyeh, T. K. Fredericks, S. E. Butt, and A. Shaar, International Journal of Project Management, vol. 24, no. 2, pp. 167-174, 2006/02/01/ (2006).

75. J. H. Michael, D. D. Evans, K. J. Jansen, and J. M. Haight, Journal of Safety Research, vol. 36, no. 2, pp. 171-179, 2005/01/01/ (2005).

76. W. N. K. Wan Ahmad, J. Rezaei, L. A. Tavasszy, and M. P. de Brito, Journal of Environmental Management, vol. 180, pp. 202-213, 2016/09/15/ (2016).

77. Q. Li, C. Ji, J. Yuan, and R. Han, Safety Science, vol. 93, pp. 266-276, 2017/03/01/ (2017).

78. S. J. Yoon, H. K. Lin, G. Chen, S. Yi, J. Choi, and Z. Rui, Safety and Health at Work, vol. 4, no. 4, pp. 201-209, 2013/12/01/ (2013).

79. Y. Huang et al., The Lancet, vol. 386, p. S72, 2015/10/01/ (2015).

80. C.-S. Park and H.-J. Kim, Automation in Construction, vol. 33, pp. 95-103, 2013/08/01/ (2013).

81. Z. Ismail, S. Doostdar, and Z. Harun, Safety Science, vol. 50, no. 3, pp. 418-423, 2012/03/01/ (2012).

82. A. Carbonari, A. Giretti, and B. Naticchia, Automation in Construction, vol. 20, no. 6, pp. 686-698, 2011/10/01/ (2011).

83. T. Zhang, S. A. Ali, L. C. Mustelier, A. A. B. Gamatche, and X. Zhang, Journal of Innovation \& Knowledge, vol. 10, p. 10, (2016).

84. B. Scharrer, Procedia-Social and Behavioral Sciences, vol. 213, pp. 855-859, (2015).

85. W. B. Lin, Expert Systems with Applications, vol. 31, no. 1, pp. 69-82, 2006/07/01/ (2006).

86. T. N. Martin and J. C. Hafer, Journal of Vocational Behavior, vol. 46, no. 3, pp. 310331, 1995/06/01/ (1995).

87. Q. He, S. Dong, T. Rose, H. Li, Q. Yin, and D. Cao, Accident Analysis \& Prevention, vol. 93, pp. 230-239, 2016/08/01/ (2016).

88. S. Han, F. Saba, S. Lee, Y. Mohamed, and F. Peña-Mora, Accident Analysis \& Prevention, vol. 68, pp. 106-116, 2014/07/01/ (2014).

89. T. Kitchel and A. L. Ball, Journal of agricultural education, vol. 55, no. 1, pp. 186199, (2014).

90. K. Amponsah-Tawiah, A. Jain, S. Leka, D. Hollis, and T. Cox, Journal of Safety Research, vol. 45, pp. 75-84, 2013/06/01/ (2013).

91. A. Stuart, Safety Science, vol. 62, pp. 409-417, 2014/02/01/ (2014).

92. M. Törner and A. Pousette, Journal of Safety Research, vol. 40, no. 6, pp. 399-409, 2009/12/01/ (2009).

93. K. W. Kim, S. J. Park, H. S. Lim, and H. H. Cho, Safety and Health at Work, vol. 8, no. 3, pp. 290-295, 2017/09/01/ (2017).

94. S. Hauge, P. Hokstad, S. Håbrekke, and M. A. Lundteigen, Reliability Engineering \& System Safety, vol. 151, pp. 34-45, 2016/07/01/ (2016).

95. L. Jiang and T. M. Probst, Journal of Safety Research, vol. 57, pp. 27-32, 2016/06/01/ (2016).

96. S. Zhang, F. Boukamp, and J. Teizer, Automation in Construction, vol. 52, pp. 29-41, 2015/04/01/ (2015).

97. M. Haifeng, Procedia Engineering, vol. 43, pp. 506-511, 2012/01/01/ (2012). 
98. M. N. Vinodkumar and M. Bhasi, Accident Analysis \& Prevention, vol. 42, no. 6, pp. 2082-2093, 2010/11/01/ (2010).

99. E. Bluff, Safety Science, vol. 74, pp. 59-69, 2015/04/01/ (2015).

100. Y. Lu, Q. Li, Z. Zhou, and Y. Deng, Safety Science, vol. 79, pp. 11-18, 2015/11/01/ (2015).

101. V. Sousa, N. M. Almeida, and L. A. Dias, Safety Science, vol. 66, pp. 75-86, 2014/07/01/ (2014).

102. Q. T. Le, D. Y. Lee, and C. S. Park, Automation in Construction, vol. 46, pp. 30-37, 2014/10/01/ (2014).

103. M. Ji, Y. Li, C. Zhou, H. Han, B. Liu, and L. He, Journal of Air Transport Management, vol. 63, pp. 126-133, 2017/08/01/ (2017).

104. C.-F. Chen and S.-C. Chen, Safety Science, vol. 62, pp. 376-385, 2014/02/01/ (2014).

105. D. Zohar, Y.-h. Huang, J. Lee, and M. M. Robertson, Transportation Research Part F: Traffic Psychology and Behaviour, vol. 30, pp. 84-96, 2015/04/01/ (2015).

106. L. Jiang and L. E. Tetrick, Accident Analysis \& Prevention, vol. 94, pp. 1-7, 2016/09/01/ (2016).

107. M. G. Helander, International Journal of Industrial Ergonomics, vol. 8, no. 3, pp. 205-223, 1991/11/01/ (1991).

108. H. Lingard, Journal of Safety Research, vol. 33, no. 2, pp. 209-230, 2002/06/01/ (2002).

109. A. Laufer, Journal of Occupational Accidents, vol. 8, no. 4, pp. 295-315, 1987/04/01/ (1987).

110. H.-y. S. Tsai, M. Jiang, S. Alhabash, R. LaRose, N. J. Rifon, and S. R. Cotten, Computers \& Security, vol. 59, pp. 138-150, 2016/06/01/ (2016).

111. S. M. Zin and F. Ismail, Procedia - Social and Behavioral Sciences, vol. 36, pp. 742751, 2012/01/01/ (2012).

112. T. Niskanen, P. Naumanen, and M. L. Hirvonen, Safety Science, vol. 50, no. 9, pp. 1929-1937, 2012/11/01/ (2012).

113. M. A. Ansary and U. Barua, International Journal of Disaster Risk Reduction, vol. 14, pp. 424-437, 2015/12/01/ (2015).

114. S. A. Kvalheim and Ø. Dahl, Journal of Safety Research, vol. 59, pp. 33-41, 2016/12/01/ (2016).

115. K. Bergheim, M. B. Nielsen, K. Mearns, and J. Eid, Safety Science, vol. 74, pp. 27-36, 2015/04/01/ (2015).

116. Y.-H. Huang et al., Applied Ergonomics, vol. 55, pp. 248-257, 2016/07/01/ (2016).

117. E. Avram, D. Ionescu, and C. L. Mincu, Procedia-Social and Behavioral Sciences, vol. 187 , pp. 679-684, (2015).

118. M. Mansoor, S. Fida, S. Nasir, and Z. Ahmad, Journal of Business Studies Quarterly, vol. 2 , no. 3 , p. 50, (2011).

119. N. Norazahar, F. Khan, B. Veitch, and S. MacKinnon, Safety Science, vol. 95, pp. 171-181, 2017/06/01/ (2017).

120. J. E. Anderson and N. Kodate, ed: Elsevier, 2015.

121. Y. Chen, B. McCabe, and D. Hyatt, Journal of Safety Research, vol. 61, pp. 167-176, 2017/06/01/ (2017).

122. Y. Shen, M. M. Tuuli, B. Xia, T. Y. Koh, and S. Rowlinson, International Journal of Project Management, vol. 33, no. 1, pp. 223-235, 2015/01/01/ (2015).

123. F. Ismail, N. Ahmad, N. A. I. Janipha, and R. Ismail, Procedia - Social and Behavioral Sciences, vol. 36, pp. 573-582, 2012/01/01/ (2012).

124. A. Hassan, A. C. A. Nor, and S. Chandrakantan, Disaster Prevention and Management: An International Journal, vol. 18, no. 5, pp. 470-477, (2009). 